\title{
Peginterferon Alfa-2a plus Ribavirin versus Interferon Alfa-2a plus Ribavirin for Chronic Hepatitis C in HIV-Coinfected Persons
}

\author{
Raymond T. Chung, M.D., Janet Andersen, Sc.D., Paul Volberding, M.D., Gregory K. \\ Robbins, M.D., Tun Liu, M.S., Kenneth E. Sherman, M.D., Ph.D., Marion G. Peters, M.D., \\ Margaret J. Koziel, M.D., Atul K. Bhan, M.D., Beverly Alston, M.D., Dodi Colquhoun, B.S. \\ Tom Nevin, M.S., George Harb, M.D., Charles van der Horst, M.D., and the AIDS Clinical \\ Trials Group A5071 Study Team \\ Massachusetts General Hospital, Boston (R.T.C., G.K.R., A.K.B.); Harvard School of Public \\ Health, Boston (J.A., T.L.); the University of California, San Francisco, San Francisco (P.V., \\ M.G.P.); the University of Cincinnati, Cincinnati (K.E.S.); Beth Israel Deaconess Medical Center, \\ Boston (M.J.K.); the National Institute of Allergy and Infectious Diseases, Bethesda, Md. (B.A.); \\ Frontier Science Technology and Research Foundation, Amherst, N.Y. (D.C.); Social and \\ Scientific Systems, Rockville, Md. (T.N.); Roche Laboratories, Nutley, N.J. (G.H.); and the \\ University of North Carolina, Chapel Hill (C.H.).
}

\section{Abstract}

BACKGROUND—Chronic hepatitis C virus (HCV) infection is a cause of major complications in persons who are also infected with the human immunodeficiency virus (HIV). However, the treatment of HCV infection in such persons has been associated with a high rate of intolerance and a low rate of response. We conducted a multicenter, randomized trial comparing peginterferon plus ribavirin with interferon plus ribavirin for the treatment of chronic hepatitis $\mathrm{C}$ in persons coinfected with HIV.

\begin{abstract}
METHODS-A total of 66 subjects were randomly assigned to receive $180 \mu \mathrm{g}$ of peginterferon alfa-2a weekly for 48 weeks, and 67 subjects were assigned to receive 6 million IU of interferon alfa-2a three times weekly for 12 weeks followed by 3 million IU three times weekly for 36 weeks. Both groups received ribavirin according to a dose-escalation schedule. At week 24, subjects who did not have a virologic response (those who had an HCV RNA level greater than or equal to $60 \mathrm{IU}$ per milliliter) underwent liver biopsy, and medications were continued in subjects with either a virologic response or histologic improvement.
\end{abstract}

RESULTS-Treatment with peginterferon and ribavirin was associated with a significantly higher rate of sustained virologic response (an HCV RNA level of less than 60 IU per milliliter 24 weeks after completion of therapy) than was treatment with interferon and ribavirin (27 percent vs. 12 percent, $\mathrm{P}=0.03$ ). In the group given peginterferon and ribavirin, only 14 percent of subjects with HCV genotype 1 infection had a sustained virologic response (7 of 51), as compared with 73

Copyright @ 2004 Massachusetts Medical Society. All rights reserved.

Address reprint requests to Dr. Chung at GRJ 825, GI Unit, Massachusetts General Hospital, Boston, MA 02114, or at rtchung@partners.org.. 
percent of subjects with an HCV genotype other than 1 (11 of 15, P<0.001). Histologic responses were observed in 35 percent of subjects with no virologic response who underwent liver biopsy.

CONCLUSIONS-In persons infected with HIV, the combination of peginterferon and ribavirin is superior to the combination of interferon and ribavirin in the treatment of chronic hepatitis $\mathrm{C}$. These regimens may provide clinical benefit even in the absence of virologic clearance. The marked discrepancy in the rates of sustained virologic response between HCV genotypes indicates that strategies are needed to improve the outcome in persons infected with HCV genotype 1.

Coinfection with hepatitis c virus (HCV) is common among persons infected with the human immunodeficiency virus (HIV), with a prevalence ranging from 4 to 92 percent depending on the underlying risk factors. Since the introduction of potent antiretroviral therapy, liver disease due to HCV coinfection has become a major source of mortality among HIV-infected persons. ${ }^{1-3}$ The progression of liver disease appears to be accelerated in such persons. ${ }^{4}$

Treatment regimens based on interferon and ribavirin are recommended for chronic hepatitis $\mathrm{C}$ but pose special concerns in persons coinfected with HIV, particularly those who are receiving antiretroviral therapy. Common side effects of treatment, such as depression, anemia, and lymphopenia, may be exacerbated. Ribavirin may interfere with thymidine analogues such as zidovudine and stavudine ${ }^{5,6}$ and may potentiate the toxic effects of didanosine. ${ }^{7}$ To date, the few studies examining the effect of interferon and ribavirin in patients coinfected with HCV and HIV have had disappointing rates of sustained virologic response and high rates of intolerable side effects. ${ }^{8,9}$ More recently, the use of peginterferon with ribavirin has significantly improved the rates of virologic response in patients with $\mathrm{HCV}$ infection alone. ${ }^{10,11}$ We therefore conducted a multicenter, randomized, controlled trial comparing peginterferon plus ribavirin with interferon plus ribavirin in the treatment of HCV infection in subjects coinfected with HIV.

\section{METHODS}

\section{SELECTION OF SUBJECTS}

The Adult AIDS Clinical Trials Group (ACTG) A5071 was a prospective study conducted at 21 ACTG sites in the United States. HIV-infected subjects 18 years of age or older were eligible to participate if they had a confirmed diagnosis of chronic hepatitis $\mathrm{C}$, as defined by an HCV RNA level of more than 600 IU per milliliter, and had not previously been treated with interferon alfa. A liver biopsy demonstrating abnormal histologic findings consistent with the presence of chronic hepatitis $\mathrm{C}$ was required within 48 weeks before study entry. Subjects with cirrhosis were eligible provided they had no evidence of hepatic decompensation (i.e., as-cites, encephalopathy, jaundice, hypoalbuminemia, or coagulopathy). Subjects who had normal or elevated serum alanine aminotransferase levels were eligible.

Subjects were stratified into two groups according to their history of HIV therapy: subjects whose antiretroviral-therapy regimen had been stable for at least 12 weeks with CD4 cell counts of more than 100 per cubic millimeter and less than 10,000 copies of HIV type 1 (HIV-1) RNA per milliliter, and subjects with CD4 cell counts of more than 300 per cubic 
millimeter who had never received antiretroviral agents and who were not planning to begin HIV therapy during the trial. Subjects were excluded if they had clinically significant anemia, neutropenia, or thrombocytopenia; renal disease; positive tests for hepatitis B surface antigen; uncontrolled cardiopulmonary disease; poorly controlled psychiatric disease; or an active HIV-related opportunistic infection.

\section{STUDY DESIGN}

Figure 1 shows the design of the study. Subjects were randomly assigned to receive either $180 \mu \mathrm{g}$ of peginterferon alfa-2a subcutaneously weekly plus ribavirin (600 mg per day for 4 weeks, $800 \mathrm{mg}$ per day for 4 weeks, and then $1000 \mathrm{mg}$ per day for the remainder of the study) or 6 million IU of interferon alfa-2a subcutaneously three times weekly for 12 weeks followed by 3 million IU subcutaneously three times weekly for the remainder of the study plus the same regimen of ribavirin used in the first group. The dose of ribavirin was increased in a stepped fashion to reduce the treatment-limiting anemia previously observed in persons coinfected with $\mathrm{HCV}$ and HIV. ${ }^{8}$ At randomization, stratification variables included the HCV genotype (genotype 1 vs. other genotypes) and antiretroviral-therapy status (current antiretroviral therapy vs. no antiretroviral therapy). The study was designed to have a statistical power of 80 percent (with a two-sided alpha value of 0.05 ) to detect an absolute difference in the rate of virologic response between groups of 30 percent. The target sample size of 132 was adjusted for a group-sequential design.

An efficacy and safety assessment was performed in all subjects at week 24 to determine whether they could continue to participate. Subjects who had a virologic response (defined as an HCV RNA level of less than 60 IU per milliliter) continued treatment until week 48, at which time a liver biopsy was performed. Subjects who had no virologic response at week 24 were required to undergo liver biopsy at that time. Subjects who had a histologic response, as defined by an improvement in the total hepatic activity index ${ }^{12}$ of at least two points, as judged by a central pathologist, were also permitted to continue treatment until week 48. Subjects who did not have a virologic response at week 24 and subjects who either had no histologic response or did not undergo liver biopsy stopped taking the study drug. Subjects were followed for an additional 24 weeks after the completion of therapy. HCV RNA levels were assessed at entry and at weeks $4,8,12,36$, and 60 with the use of a quantitative RNA assay (lower limit of detection, $600 \mathrm{IU}$ per milliliter, Roche Cobas Amplicor 2.0) and at weeks 24, 48, and 72 with the use of a qualitative RNA assay (lower limit of detection, $60 \mathrm{IU}$ per milliliter, Roche Cobas Amplicor 2.0).

HCV genotyping was performed on all subjects at entry with the use of a line-probe assay (LiPA, Innogenetics). Results were reported as genotype 1 or a genotype other than 1 .

The institutional review boards of the participating sites approved the protocol, and all subjects provided written informed consent. An external data and safety monitoring board reviewed the study design and the results of one interim analysis.

The study was funded by the National Institutes of Health. The drugs and diagnostic kits for the detection of HCV RNA were provided by Roche Laboratories. The study investigators had access to all of the study data, took responsibility for the accuracy of the analysis, and 
had full and independent authority over the preparation of the manuscript and decisions concerning publication.

\section{ASSESSMENT OF EFFICACY AND SAFETY}

Because of concern about the safety of administering these drugs to subjects who were coinfected with HIV, we used the primary end points of viro-logic response and safety at week 24. Secondary end points included a sustained virologic response, defined by an HCV RNA level of less than 60 IU per milliliter 24 weeks after the completion of therapy, allowing a 6-week window for the sample; a viro-logic response at the end of treatment, as defined by an HCV RNA level of less than 60 IU per milliliter at the completion of therapy; an early virologic response, as defined by the clearance of HCV RNA or a reduction in HCV RNA levels by more than $2 \log$ (on a base-10 scale) IU per milliliter at 12 weeks of treatment; a histologic response; changes in the control of HIV disease, as defined by changes in the CD4 cell count, percentage of CD4 cells, and HIV-1 RNA levels; or development of an AIDS-defining illness. HIV-1 RNA was assessed with the use of an assay (Roche Cobas Amplicor 2.0) with a lower limit of detection of 50 copies per milliliter. All data were analyzed according to the intention to treat.

Safety was assessed at weeks 1,2, and 4 and every 4 weeks thereafter and 12 and 24 weeks after the discontinuation of the study drug. Specific end points were the incidence of grade 3 (severe) or 4 (life-threatening) adverse events ${ }^{13}$ and the premature discontinuation of treatment.

Subjects who discontinued treatment prematurely because of intolerance to the study drug were encouraged to remain in the study. Stepwise reductions in the doses of peginterferon to 135,90 , or $45 \mu \mathrm{g}$ weekly and reductions in ribavirin doses to $600 \mathrm{mg}$ per day were permitted to manage adverse events or abnormalities in laboratory values that reached predetermined thresholds of severity. If the adverse event resolved or improved, a return to the initial dosing level was permitted unless the subject had received the reduced dose for more than four weeks. Subjects were withdrawn from treatment if they missed three or more consecutive doses or at the discretion of the investigator. The use of supplemental hematopoietic growth factors (epoietin alfa and filgrastim) was permitted.

\section{STATISTICAL ANALYSIS}

Associations between dichotomous variables were evaluated with Fisher's exact test. Associations involving ordered categorical data or continuous data were evaluated with a Wilcoxon test adjusted for ties. Univariate- and multicovariate-adjusted P values for the association of the virologic response at week 24 with covariates were evaluated with logistic regression stratified according to the HCV genotype and HIV treatment history. All P values are two-sided. Univariate analyses of sustained virologic response were performed with logrank tests, and multicovariate analyses with proportional-hazards regression. Because of the limited sample size and because sustained virologic response was not a primary objective, these tests were not stratified according to the group or the HCV genotype. The proportion of subjects who continued to have sustained virologic response was estimated with the use of the life-table method. 


\section{RESULTS \\ BASELINE CHARACTERISTICS}

A total of 134 subjects were enrolled between December 2000 and June 2001. One subject was excluded from analyses because he did not meet the entry criteria; he did not receive treatment. Table 1 depicts the baseline characteristics of the 133 eligible subjects. All received at least one dose of study medication. The pretreatment characteristics of the subjects in the two groups were similar, including age, sex, race or ethnic group, and performance status. Eighty-six percent of subjects were receiving stable antiretroviral therapy; 60 percent of subjects had fewer than 50 copies of HIV-1 RNA per milliliter. The median CD4 cell counts were nearly 500 per cubic millimeter. The median HCV RNA levels were high, with levels exceeding $10^{6} \mathrm{IU}$ per milliliter in 82 percent of subjects. Seventy-eight percent had HCV genotype 1 infection, and 67 percent had abnormal alanine aminotransferase levels. Baseline histologic findings were similar in the two groups. Ten percent of subjects had evidence of cirrhosis (as defined by a fibrosis stage of 5 or 6 ).

\section{VIROLOGIC RESPONSE}

The rates of virologic response at week 24 and at the end of treatment were higher in the group given peginterferon and ribavirin than in the group given interferon and ribavirin (Table 2). At week 24, 44 percent of subjects in the group given peginterferon and ribavirin had a virologic response, as compared with 15 percent of those in the group given interferon and ribavirin $(\mathrm{P}<0.001)$, and the rates of virologic response at the end of treatment were 41 percent and 12 percent, respectively $(\mathrm{P}<0.001)$ (Table 2).

Receipt of peginterferon and ribavirin was associated with a significantly higher rate of sustained virologic response (27 percent, vs. 12 percent in the group given interferon and ribavirin; $\mathrm{P}=0.03$ ). As with $\mathrm{HCV}$ monoinfection, there was a significant disparity in response rates in both groups between subjects infected with HCV genotype 1 and those infected with other HCV genotypes. For those with genotype 1 infections, the rate of sustained virologic response was only 14 percent in the group given peginterferon and ribavirin and 6 percent in the group given interferon and ribavirin, whereas for those infected with other HCV genotypes (predominantly genotypes 2 and 3), the respective rates of sustained virologic response were 73 percent and 33 percent $(\mathrm{P}<0.001$ for the comparison with genotype 1 infections). The observed decrement in the rate of sustained virologic response from the end-of-treatment virologic response in the group given peginterferon and ribavirin was attributable to a high relapse rate among those with HCV genotype 1 infection.

\section{PREDICTORS OF A SUSTAINED VIROLOGIC RESPONSE}

Receipt of peginterferon and ribavirin, an $\mathrm{HCV}$ genotype other than 1, the absence of prior injection-drug use, a detectable level of HIV-1 RNA at entry, and a Karnofsky score of 100 were predictive of a sustained virologic response in univariate analysis (Table 3). In multivariate analysis, all of these variables but the Karnofsky score independently predicted a sustained virologic response. The baseline CD4 cell count, percentage of CD4 cells, age, race or ethnic group, body weight, HCV RNA level, use or nonuse of any antiretroviral therapy, use or nonuse of protease inhibitors, baseline HIV RNA level, use or nonuse of 
supplemental growth factors, and pretreatment histologic findings were not predictive of a sustained virologic response.

\section{EARLY VIROLOGIC RESPONSE}

Of the 106 subjects in whom HCV RNA levels were measured at week 12 (Fig. 2), 43 (41 percent) had an early virologic response. Twenty-two of these 43 subjects (51 percent) had a sustained virologic response. In contrast, none of the 63 subjects who did not have an early virologic response had a sustained virologic response (negative predictive value, 100 percent).

\section{HISTOLOGIC RESPONSE}

Among the subjects with no virologic response at week 24, 45 of 57 subjects in the group given interferon and ribavirin (79 percent) underwent liver biopsy, as did 26 of 37 subjects in the group given peginterferon and ribavirin (70 percent). A histo-logic response was observed in 25 of these 71 subjects ( 35 percent), 36 percent of such subjects in the group given interferon and ribavirin and 35 percent of such subjects in the group given peginterferon and ribavirin. The magnitude of the reduction in HCV RNA levels among subjects with a histologic response did not differ from that among those without a histologic response, indicating that a partial virologic response did not predict histologic improvement.

Among the 39 subjects with a virologic response at week 24, 27 underwent a biopsy at week 48. Fourteen of these 27 subjects (52 percent) had a histo-logic improvement, 11 (41 percent) had no change, and 2 (7 percent) had worsening disease.

\section{SAFETY AND ADVERSE EVENTS}

Eight subjects in each group (12 percent) were prematurely withdrawn from treatment because of abnormalities in laboratory values or other adverse events, and the rates were similar to the rates of premature withdrawal in studies of subjects with HCV monoinfection who received similar treatments. ${ }^{12,13}$ Of the 16 such subjects, 3 declined further participation and 1 died of causes unrelated to $\mathrm{HCV}$ infection or treatment. The remaining 12 were withdrawn from the study because of either neuropsychiatric issues (primarily depression) or the need to manage multiple signs and symptoms and abnormal laboratory values. Similar numbers of subjects in each group had grade 2 or 3 influenza-like symptoms and grade 2 or 3 depression during treatment (Table 4). There were no significant differences between groups in the frequency of grade 2 or higher decreases in hemoglobin; such decreases occurred in few subjects. Neutro-phil counts decreased in both groups, particularly during the first two weeks of treatment. Two subjects in the group given peginterferon and ribavirin discontinued therapy because of grade 4 neutropenia (defined as fewer than 500 neutrophils per cubic millimeter). In six others (three in each group), grade 4 neutropenia was successfully managed with a dose reduction, with or without the addition of hematopoietic growth factor. Grade 4 thrombocytopenia occurred in only one subject in the group given peginterferon and ribavirin.

Although grade 2 or 3 elevations in lipase were observed in nine subjects in each group during the first 24 weeks, there was only one clinically significant episode of pancreatitis 
requiring hospitalization and the discontinuation of treatment at week 16 . The subject was also receiving didanosine. Of the 18 subjects with lipase elevations of grade 2 or higher, only 4 were taking didanosine. A single grade 3 elevation in lactate was noted in one subject, but it did not require the discontinuation of treatment. One subject died of complications related to Hodgkin's disease; this event was thought to be unrelated to the study medications. There were no AIDS-defining illnesses.

\section{EFFECTS ON THE CONTROL OF HIV DISEASE}

The median CD4 cell count fell from entry to week 24 in both groups (by 130 cells per cubic millimeter in the group given peginterferon and ribavirin and by 103 cells per cubic millimeter in the group given interferon and ribavirin, $\mathrm{P}=0.04$ ); however, the percentage of CD4 cells actually increased in both groups (by 3.5 percent and 3.0 percent, respectively). For the subjects who continued treatment until week 48, the absolute CD4 cell count did not decrease further and returned to baseline 24 weeks after treatment was stopped.

A total of 119 subjects had data on HIV-1 RNA levels available at baseline and week 24 . Fifty-four percent of subjects in the group given interferon and ribavirin and 52 percent of those in the group given peginterferon and ribavirin had undetectable levels of HIV-1 RNA at both times. Another 29 percent in each group had detectable levels of HIV-1 RNA at both times. Six percent of subjects in the group given interferon and ribavirin and 5 percent of those given peginterferon and ribavirin had undetectable levels at baseline and detectable levels of HIV-1 RNA at 24 weeks. Eleven percent and 14 percent, respectively, had initially detectable levels that were undetectable at 24 weeks.

\section{DISCUSSION}

We conducted a multicenter, randomized, controlled trial of peginterferon and ribavirin and interferon and ribavirin in subjects who were coinfected with HCV and HIV. The combination of peginterferon and ribavirin was significantly more effective in achieving a sustained virologic response than was the combination of interferon and ribavirin. However, the rate of sustained virologic response with peginterferon and ribavirin therapy was considerably lower than the rates among patients with HCV monoinfection who received similar therapy, ${ }^{10,11}$ despite the relatively high CD4 cell counts in our cohort.

We observed an even more dramatic disparity in the response of different HCV genotypes than was observed in patients with HCV monoinfection. The rate of sustained virologic response after peginterferon and ribavirin in HIV-infected subjects with HCV genotype 2 or 3 infection approached historical rates in subjects with HCV monoinfection (which are 75 to 82 percent), but the rate of response to interferon and ribavirin was lower. ${ }^{10,11}$ However, there was a marked dropoff in the rate of sustained response among subjects with HCV genotype 1 and HIV infection, as compared with historical rates among subjects with HCV monoinfection (42 to 45 percent). ${ }^{10,11}$ Among subjects who received peginterferon and ribavirin, the large decrease in the rate of sustained virologic response was driven primarily by a high relapse rate in those with HCV genotype 1 infection. The use of peginterferon and ribavirin in patients coinfected with HCV genotype 1 and HIV should therefore be carefully weighed against this low projected rate of response. 
There are several potential explanations for the diminished rates of antiviral response: $\mathrm{HCV}$ RNA levels are higher in subjects with HIV coinfection than in those with HCV monoinfection; the cumulative doses of ribavirin received in this dose-escalation regimen may have been, either because of the study design or because of dose reductions, insufficient to prevent relapse; and qualitative rather than quantitative defects in the cellular immune response may underlie the failure to clear HCV. Investigation of new treatment strategies, including use of dose-optimized ribavirin, will be required to improve response rates and decrease relapse rates among patients coinfected with HCV genotype 1 and HIV.

Adherence to treatment has been cited as a potentially important factor in determining the outcome. We did not specifically examine adherence, since detailed pill or injection counts were not performed. Although information regarding dose-modification events is available to us, the complex nature of the study design, in which only subjects with a virologic response or subjects with a histo-logic response but not a virologic response were permitted to continue therapy beyond 24 weeks (a total of 64 subjects), limits our ability to perform a meaningful analysis of the relationship between adherence and a sustained virologic response.

The rate of premature discontinuation of 12 percent was similar to the rates in studies of HIV-negative subjects with chronic hepatitis $\mathrm{C}^{10,11}$ and was perhaps lower than those in prior studies of interferon and ribavirin in subjects coinfected with HCV and HIV, in which dropout rates approached 30 percent. ${ }^{8,9}$ This favorable outcome may have been attributable to the dosing schedule for ribavirin, which was designed to maximize the retention of study subjects.

Furthermore, antiviral therapy for HCV had no adverse effect on the control of HIV disease. Interferon has broadly suppressive effects on leukocytes, and the finding of reduced CD4 cell counts was therefore not surprising; however, the percentage of CD4 cells actually increased, and HIV-1 RNA levels did not change appreciably during the study. Most important, no clinical progression of HIV to AIDS was observed during the study period.

The surprising finding that the presence of detectable HIV-1 RNA levels at entry was associated with a sustained virologic response to HCV therapy may reflect several factors: the enrollment of subjects with relatively preserved CD4 cell counts who had not received antiretroviral therapy or of subjects who had not been receiving antiretroviral therapy long enough to have complete virologic suppression and the association of HIV suppression with increases in HCV RNA. ${ }^{14}$ Alternatively, given that this finding was the result of an exploratory analysis of a secondary end point, it may represent a type I error. Confirmation in other studies will be important.

Because of the importance of the progression of liver disease in subjects who are coinfected with HCV and HIV, we also assessed histologic responses in both those with a virologic response and those without a virologic response. It is consistent with the observed effects of combination antiviral therapy on liver histologic findings that the majority of subjects with a virologic response had a histologic response. We also found that among subjects without a virologic response who underwent liver biopsy, over one third had histologic evidence of 
improvement, despite the absence of a significant decrease in HCV viremia. These data suggest that interferon-based therapy has benefits that are independent of its antiviral effects and support the need for investigation of maintenance strategies, especially among subjects coinfected with HCV and HIV who have moderate-to-advanced fibrosis. Maintenance therapy with interferon could be given for extended periods at doses that do not clear the virus but may halt or slow the progression of liver fibrosis, as has been done in subjects with HCV monoinfection. ${ }^{15}$ These data take on even greater relevance in the light of the low rates of response to interferon therapy in subjects coinfected with HCV genotype 1 and HIV.

Since the absence of markers of an early viro-logic response uniformly predicted the futility of treatment, early discontinuation of antiviral therapy at 12 weeks should be considered in patients with minimal or no fibrosis who do not have a reduction in HCV RNA levels by a factor of 100 from baseline. However, therapy should be continued in patients with more advanced disease, since the goal of treatment is slowing the progression of liver disease rather than eradicating the virus.

\section{Acknowledgments}

Supported by General Clinical Research Center grants (RR00046, RR00096, and RR00044) and a Center for AIDS Research grant (P30-AI27763D) from the National Institute of Allergy and Infectious Diseases and by grants (AI25868, AI27661, AI27670, AI27675, AI46370, AI25897, AI50410, AI046376, and AI27659) from the ACTG.

Dr. Andersen reports having received consulting fees from Tibotec; Dr. Chung grant support from Roche Laboratories and Schering-Plough; Dr. Peters lecture fees or grant support from Axcan, Gilead, Roche, and Schering-Plough; Dr. Robbins consulting fees, lecture fees, or grant support from Abbott, Agouron, Bristol-Myers Squibb, and GlaxoSmithKline; Dr. Sherman consulting fees, lecture fees, or grant support from Bristol-Myers Squibb, Hoffmann- La Roche, Intermune, PharmaResearch, and Schering-Plough; and Dr. Volberding consulting fees, lecture fees, or grant support from Gilead, Bristol-Myers Squibb, GlaxoSmithKline, OrthoBioTech, Pfizer, and Shire.

We are indebted to the following for their participation in the study: Amy Sbrolla, Harvard University, Massachusetts General Hospital (ACTG site A0101); Michael Scott and Elizabeth Race, University of Texas, Southwestern Medical Center (ACTG site A3751); Alex Chall, Jackie Kaufman, and Dickens Theodore, University of North Carolina (ACTG site A3201); Chris Hurley and Mary Shoemaker, University of Rochester Medical Center (ACTG site A1101); Richard Hutt and Charles Gonzalez, New York University, Bellevue (ACTG site A0401); Thomas Merigan, Debbie Slamowitz, and Jane Norris, Stanford University (ACTG site A0501); Diane Daria and Josette Robinson, University of Cincinnati (ACTG site A2401); James Richardson and Greta Clement, Indiana University Hospital (ACTG site A2601); Jolene Noel-Connor and Steven Chang, Columbia University (ACTG site A7802); Donna Mildvan and David J. Clain, Beth Israel Medical Center (ACTG site A2851); Nancy Hanks (Hawaii AIDS Clinical Research Program) and Scott Souza (Queen's Medical Center Hawaii AIDS Clinical Research Program), University of Hawaii (ACTG site A5201); M. Graham Ray and Gregory Fitz, University of Colorado Health Sciences Center (ACTG site A6101); Charles Bradley Hare and Joann Volinski, San Francisco General Hospital (ACTG site A0801); Margaret A. Fischl and Nancey Bathurst, University of Miami (ACTG site A0901); Michael Conklin and Judith Aberg, Washington University (ACTG site A2101); Joel Maslow and Rosanne Burke, University of Pennsylvania, Philadelphia (ACTG site A6201); Jack Stapleton and Julie Katseres, University of Minnesota (ACTG site A1501); Patrick Lynch and Robert Murphy, Northwestern University (ACTG site A2701); and Tari Gilbert and Gerald Mo-reno, University of California, San Diego, Antiviral Research (ACTG site A0701); to Roche Laboratories for providing the study drug and HCV RNA monitoring kits; and to Susan Breen for assistance in the preparation of the manuscript.

\section{References}

1. Bica I, McGovern B, Dhar R, et al. Increasing mortality due to end-stage liver disease in patients with human immunodeficiency virus infection. Clin Infect Dis. 2001; 32:492-7. [PubMed: 11170959] 
2. Lesens O, Deschenes M, Steben M, Belanger G, Tsoukas CM. Hepatitis C virus is related to progressive liver disease in human immunodeficiency virus-positive hemophiliacs and should be treated as an opportunistic infection. J Infect Dis. 1999; 179:1254-8. [PubMed: 10191232]

3. Darby SC, Ewart DW, Giangrande PL, et al. Mortality from liver cancer and liver disease in haemophilic men and boys in UK given blood products contaminated with hepatitis C. Lancet. 1997; 350:1425-31. [PubMed: 9371165]

4. Benhamou Y, Bochet M, Di Martino V, et al. Liver fibrosis progression in human immunodeficiency virus and hepatitis C virus coinfected patients. Hepatology. 1999; 30:1054-8. [PubMed: 10498659]

5. Baba M, Pauwels R, Balzarini J, Herdewijn P, De Clercq E, Desmyter J. Ribavirin antagonizes inhibitory effects of pyrimidine $2^{\prime}, 3^{\prime}$-dideoxynucleosides but enhances in hibitory effects of purine $2^{\prime}, 3^{\prime}$-dideoxynucleosides on replication of human immunodeficiency virus in vitro. Antimicrob Agents Chemother. 1987; 31:1613-7. [PubMed: 3435108]

6. Vogt MW, Hartshorn KL, Furman PA, et al. Ribavirin antagonizes the effect of azidothymidine on HIV replication. Science. 1987; 235:1376-9. [PubMed: 2435003]

7. Lafeuillade A, Hittinger G, Chadapaud S. Increased mitochondrial toxicity with ribavirin in HIV/HCV coinfection. Lancet. 2001; 357:280-1. [PubMed: 11214134]

8. Landau A, Batisse D, Van Huyen JP, et al. Efficacy and safety of combination therapy with interferon-alpha2b and ribavirin for chronic hepatitis C in HIV-infected patients. AIDS. 2000; 14:839-44. [PubMed: 10839592]

9. Zylberberg H, Benhamou Y, Lagneaux JL, et al. Safety and efficacy of interferon-ribavirin combination therapy in HCV-HIV coin-fected subjects: an early report. Gut. 2000; 47:694-7. [PubMed: 11034587]

10. Manns MP, McHutchison JG, Gordon SC, et al. Peginterferon alfa-2b plus ribavirin compared with interferon alfa-2b plus ribavirin for initial treatment of chronic hepati tis $\mathrm{C}$ : a randomised trial. Lancet. 2001; 358:958-65. [PubMed: 11583749]

11. Fried MW, Shiffman ML, Reddy KR, et al. Peginterferon alfa-2a plus ribavirin for chronic hepatitis C virus infection. N Engl J Med. 2002; 347:975-82. [PubMed: 12324553]

12. Ishak K, Baptista A, Bianchi L, et al. Histological grading and staging of chronic hepatitis. J Hepatol. 1995; 22:696-9. [PubMed: 7560864]

13. Division of AIDS table for grading severity of adult adverse experiences. National Institute of Allergy and Infectious Diseases; Bethesda, Md.: 1992.

14. Chung RT, Evans SR, Yang Y, et al. Immune recovery is associated with persistent rise in hepatitis $\mathrm{C}$ virus RNA, infrequent liver test flares, and is not impaired by hepatitis $\mathrm{C}$ virus in co-infected subjects. AIDS. 2002; 16:1915-23. [PubMed: 12351951]

15. Shiffman ML, Hofmann CM, Contos MJ, et al. A randomized, controlled trial of maintenance interferon therapy for patients with chronic hepatitis $\mathrm{C}$ virus and persistent viremia. Gastroenterology. 1999; 117:1164-72. [PubMed: 10535880] 


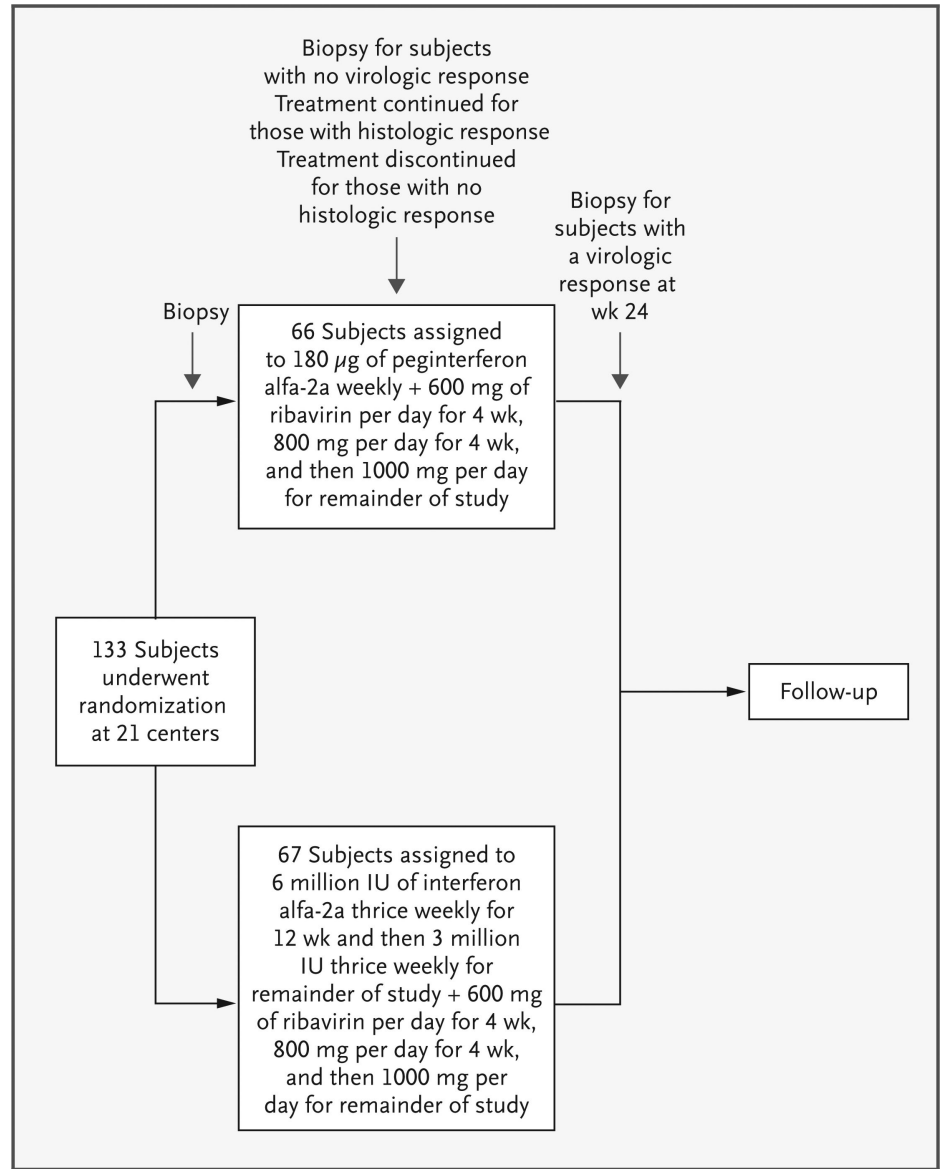

Figure 1.

Study Design. 


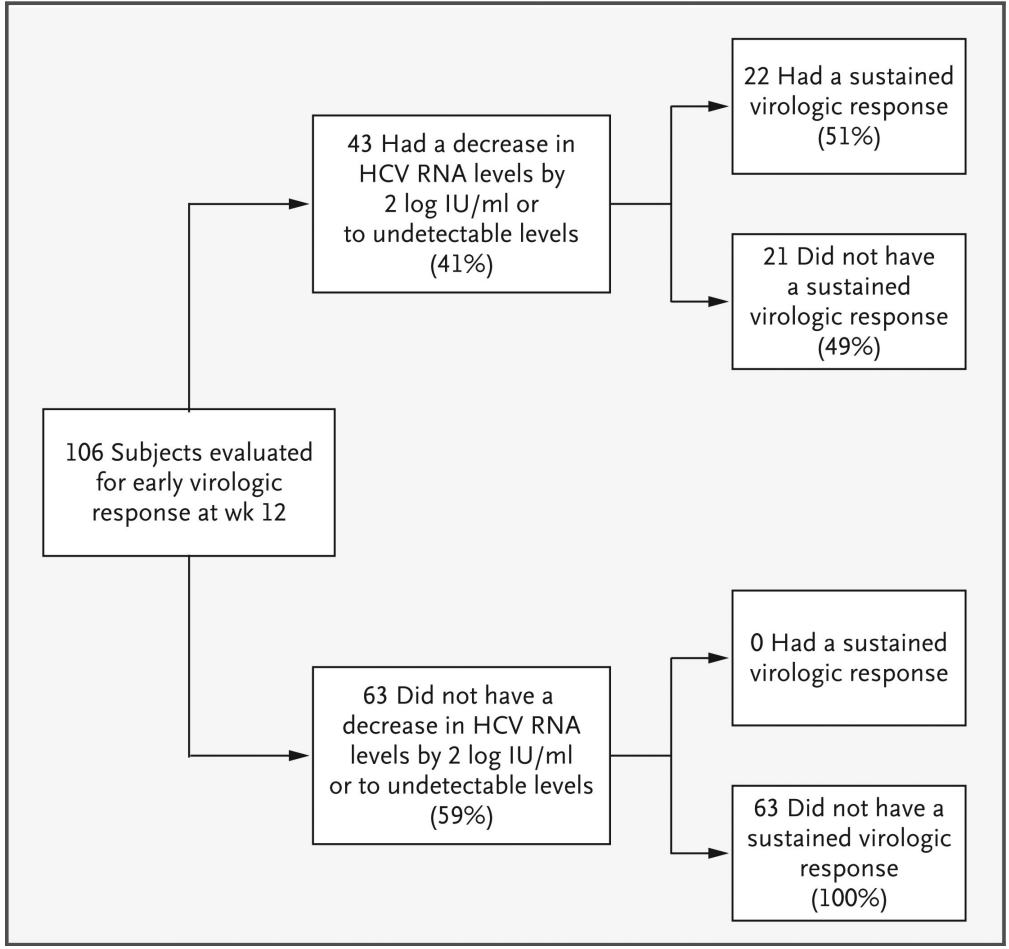

Figure 2.

Predictive Value of an Early Virologic Response. 


\section{Table 1}

Baseline Characteristics ofthe Subjects.

\begin{tabular}{|c|c|c|}
\hline Characteristic & Interferon and Ribavirin $(\mathrm{N}=67)$ & Peginterferon and Ribavirin $(\mathrm{N}=66)$ \\
\hline Male sex $(\%)$ & 85 & 79 \\
\hline \multicolumn{3}{|l|}{ Race or ethnic group $(\%)^{\dagger}$} \\
\hline White & 46 & 50 \\
\hline Black & 34 & 32 \\
\hline Hispanic & 12 & 15 \\
\hline Other & 8 & 3 \\
\hline Age (yr) & 44 & 45 \\
\hline Karnofsky scorex & 90 & 90 \\
\hline Median CD4 cell count (no./mm³) & 453 & 495 \\
\hline HIV-1 RNA level <50 copies/ml (\%) & 60 & 61 \\
\hline Receiving antiretroviral therapy $(\%)^{*}$ & 87 & 85 \\
\hline HCV RNA level $\left(\times 10^{-6} \mathrm{IU} / \mathrm{ml}\right)^{\S}$ & $6.2 \pm 0.3$ & $6.2 \pm 0.4$ \\
\hline 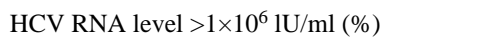 & 82 & 83 \\
\hline HCV genotype $1(\%)^{*}$ & 78 & 77 \\
\hline Abnormal alanine aminotransferase level (\%) & 68 & 66 \\
\hline Median hepatitis activity index score ${ }^{q}$ & 5.0 & 5.0 \\
\hline Median fibrosis score $/ /$ & 2.0 & 2.0 \\
\hline Cirrhosis $(\%)^{* *}$ & 9 & 11 \\
\hline \multicolumn{3}{|c|}{ There were no significant differences between the groups. } \\
\hline \multicolumn{3}{|c|}{ Race or ethnic group was self-reported by the subjects. } \\
\hline \multicolumn{3}{|l|}{ This was a stratification variable. } \\
\hline \multicolumn{3}{|l|}{$\S_{\text {Plus-minus values are means } \pm \text { SD. }}$} \\
\hline \multicolumn{3}{|c|}{${ }^{I I}$ Scores can range from 0 to 18 , with higher scores indicating more activity. ${ }^{12}$} \\
\hline Scores can range from 0 to 6 , with higher scor & dicating more extensive fi-brosis. & \\
\hline
\end{tabular}


Table 2

Rates ofVirologic Response.

\begin{tabular}{|c|c|c|c|c|c|c|c|}
\hline \multirow[t]{3}{*}{ Virologic Response } & \multirow{3}{*}{$\begin{array}{c}\text { Interferon } \\
\text { and } \\
\text { Ribavirin } \\
(\mathrm{N}=67)\end{array}$} & \multirow{2}{*}{$\begin{array}{c}\text { Peginterferon } \\
\text { and Ribavirin } \\
\quad(\mathbf{N}=66)\end{array}$} & \multirow[t]{2}{*}{ P Value } & \multicolumn{2}{|c|}{ Genotype 1 Infection } & \multicolumn{2}{|c|}{ Non-Genotype 1 Infection } \\
\hline & & & & $\begin{array}{c}\text { Interferon } \\
\text { and } \\
\text { Ribavirin } \\
(\mathbf{N}=52)\end{array}$ & $\begin{array}{c}\text { Peginterferon } \\
\text { and Ribavirin } \\
\quad(\mathbf{N}=51)\end{array}$ & $\begin{array}{l}\text { Interferon } \\
\text { and } \\
\text { Ribavirin }(\mathbf{N} \\
\quad=15)\end{array}$ & $\begin{array}{l}\text { Peginterferon } \\
\text { and Ribavirin } \\
\quad(\mathrm{N}=15)\end{array}$ \\
\hline & & no. $(\%)$ & & \multicolumn{2}{|c|}{ no. $(\%)$} & \multicolumn{2}{|c|}{ no. $(\%)$} \\
\hline At week 24 & $10(15)$ & $29(44)$ & $<0.001$ & $4(8)$ & $17(33)^{*}$ & $6(40)$ & $12(80)$ \\
\hline At end of treatment & $8(12)$ & $27(41)$ & $<0.001$ & $3(6)$ & $15(29)$ & $5(33)$ & $12(80)^{\dagger}$ \\
\hline Sustained & $8(12)$ & $18(27)$ & 0.03 & $3(6)$ & $7(14)$ & $5(33)^{\dagger}$ & $11(73)^{\dagger+}$ \\
\hline
\end{tabular}

${ }^{*} \mathrm{P}=0.001$ for the comparison with the group given interferon and ribavirin.

${ }^{\dagger} \mathrm{P}<0.001$ for the comparison with the subjects in the same group with a genotype 1 infection.

${ }^{\ddagger} \mathrm{P}=0.07$ for the comparison with the group given interferon and ribavirin with a non-genotype 1 infection. 
Table 3

Predictors of a Sustained Virologic Response.

Factor
Treatment with peginterferon and ribavirin (vs. interferon and
ribavirin)
Non-genotype 1 infection (vs. genotype 1 infection)
Prior injection-drug use (vs. no prior use)
HIV-1 RNA detectable at baseline (vs. undetectable)
Karnofsky score of 100 (vs. <100)

Univariate Analysis
0.03
$<0.001$
0.039
0.046
0.007

P Value

Multivariate Analysis

0.03

0.001

0.008

$<0.001$

0.009

0.023

$*$
Odds Ratio (95\% CI)

$4.76(1.49-15.2)$

$15.8(4.94-50.5)$

$0.48(0.27-0.83)$

$3.55(1.19-10.6)$

This factor did not meet criteria for retention in the multicovariate model. 


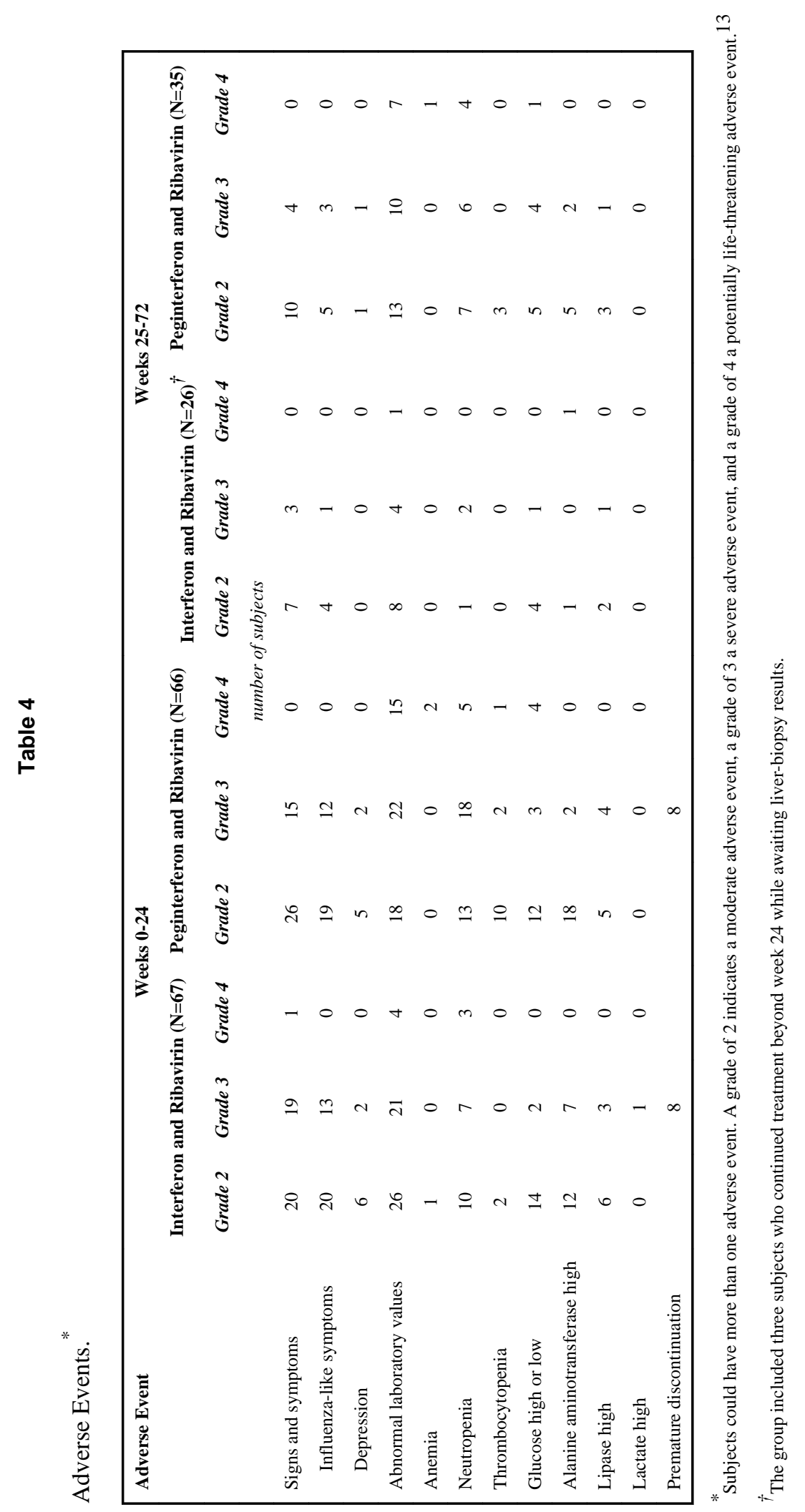

N Engl J Med. Author manuscript; available in PMC 2014 July 28. 